\title{
Anti-CD3/CD38 Bispecific Monoclonal Antibody AMG 424
}

National Cancer Institute

\section{Source}

National Cancer Institute. Anti-CD3/CD38 Bispecific Monoclonal Antibody AMG 424. NCI

Thesaurus. Code C153147.

A humanized, bispecific monoclonal antibody (BsAb) targeting CD3, a T-cell surface antigen, and CD38, a human cell surface glycoprotein and tumor-associated antigen (TAA), with potential antineoplastic activity. Upon intravenous administration, antiCD3/CD38 bispecific monoclonal antibody AMG 424 binds to both CD3 on T-cells and CD38 expressed on tumor cells. The resulting cross-linkage may trigger a potent cytotoxic T-lymphocyte (CTL) response against CD38-expressing tumor cells. CD38, a type II transmembrane glycoprotein, is present on various immune cells and hematologic malignancies; its expression has been correlated with poor prognosis. 